\title{
CART Initiatives in Europe
}

\author{
Alvaro Urbano-Ispizua and Michael Hudecek
}

The efficacy of chimeric antigen receptor T cells (CARTs) in B cell neoplasms, ALL, large B cell lymphoma, and now multiple myeloma has been one of the great achievements in the fight against cancer in recent decades (Porter et al. 2011). However, there is still a need to increase the proportion of responses (especially in NHL) (Locke et al. 2019) and to decrease the proportion of relapse (especially in ALL) (Grupp et al. 2013). More importantly, currently, commercial CAR-T products are not available for $\mathrm{T}$ cell neoplasms, myeloid malignant haemopathies, or solid tumours. As a reflection of the necessary efforts to expand the efficacy of CARTs, more than 500 clinical trials are currently underway worldwide, mostly led by American or Chinese groups. Unfortunately, European institutions are underrepresented in these initiatives. It is our duty to push and harmonize European academic clinical trials. We identified 35 early clinical trials promoted by European groups in Eudract and ClinTrialsGov (20 February 2021) (Table 5.1). Among them, 20 are initiatives from academic institutions, and 15 are initiatives from European companies allied with European academic institutions. In this summary, CART clinical trials promoted by European academic centres or by small to medium European companies are listed. The aim is to inform European groups treating haemato-oncology diseases of the current situation in this field, facilitating the inclusion of patients in these clinical trials. We aim to support the groups promoting these studies to increase collaboration.

\footnotetext{
A. Urbano-Ispizua

Institute of Hematology and Oncology. Hospital Clinic of Barcelona. University of Barcelona, Barcelona, Spain

e-mail: aurbano@clinic.cat

M. Hudecek ( $\square)$

Department of Internal Medicine II, University Hospital of Würzburg, Würzburg, Germany

e-mail: Hudecek_M@ukw.de 


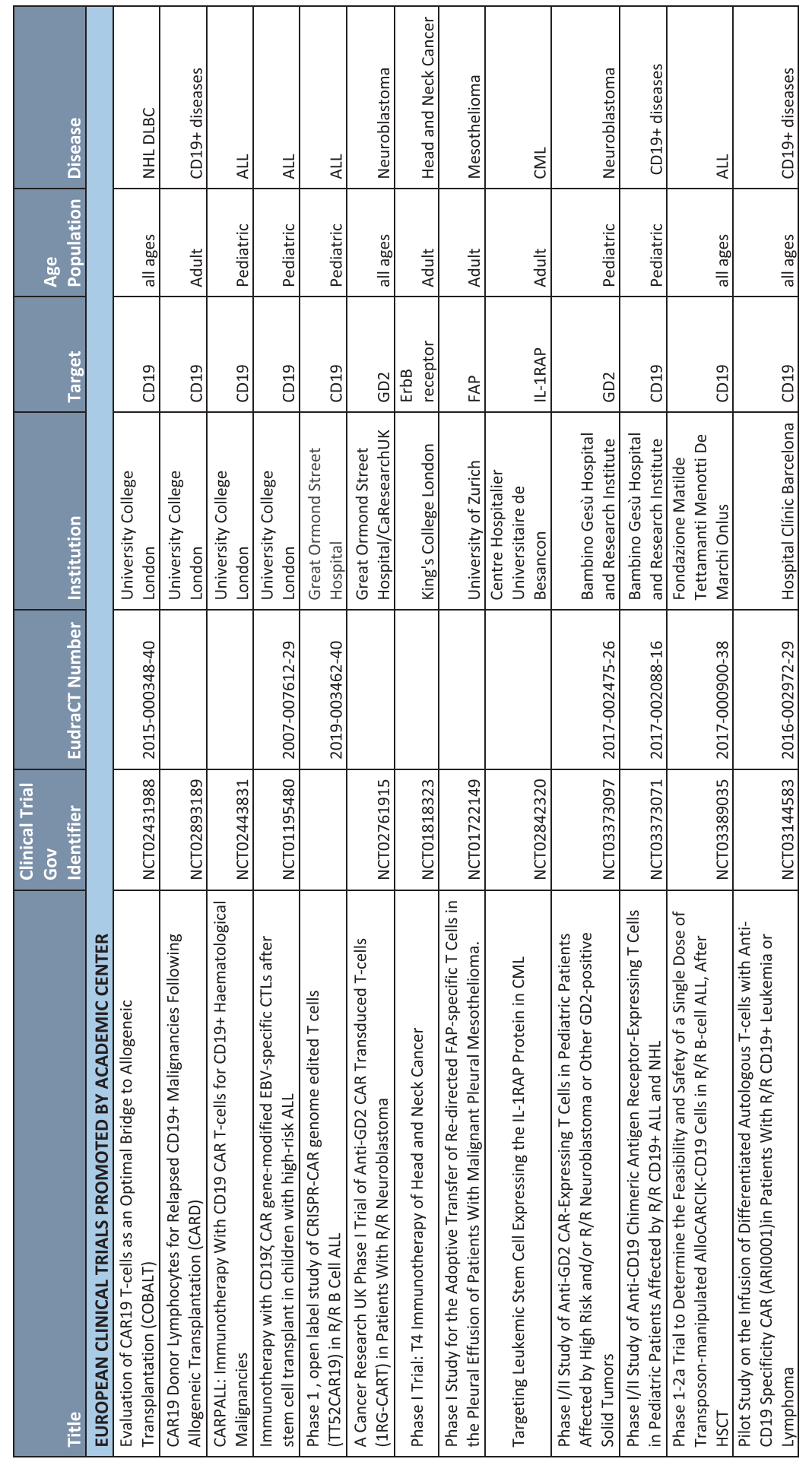




\begin{tabular}{|c|c|c|c|c|c|c|c|c|c|c|c|c|c|c|}
\hline$\sum$ & $\bar{z}$ & 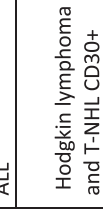 & 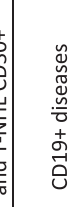 & 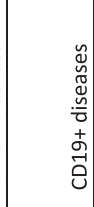 & 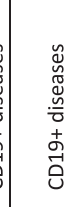 & 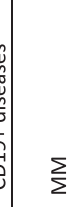 & & $\sum_{\Sigma}^{\sum}$ & $\vec{\psi}$ & 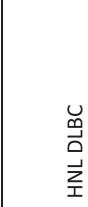 & $\begin{array}{l}\sum_{i} \\
i \\
r\end{array}$ & 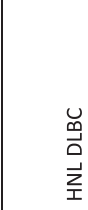 & $\sum_{\Sigma}^{\sum}$ & $\vec{\varangle}$ \\
\hline$\frac{5}{\frac{5}{4}}$ & 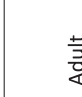 & $\frac{\vec{n}}{\frac{3}{4}}$ & 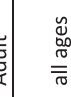 & 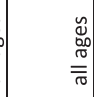 & 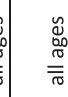 & $\frac{4}{\frac{3}{8}}$ & & 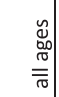 & 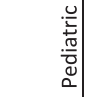 & $\frac{\frac{n}{3}}{\frac{3}{4}}$ & $\frac{\frac{n}{3}}{\frac{3}{4}}$ & $\frac{\frac{n}{3}}{\frac{3}{4}}$ & $\frac{ \pm}{3}$ & $\frac{\frac{n}{3}}{\frac{3}{4}}$ \\
\hline 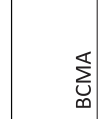 & ชิ & O̊̊ & $\overrightarrow{0}$ & वे & $\tilde{8}$ & 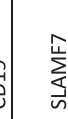 & & 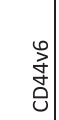 & 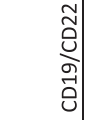 & 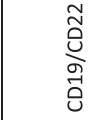 & $\begin{array}{l}\vec{J} \\
\text { 兽 }\end{array}$ & $\begin{array}{l}\tilde{\widetilde{U}} \\
\frac{0}{9} \\
\stackrel{0}{0}\end{array}$ & ڤે & वे \\
\hline 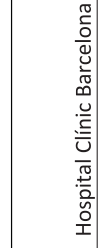 & 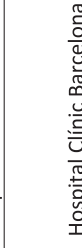 & 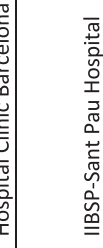 & 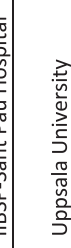 & 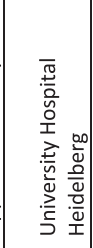 & 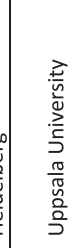 & 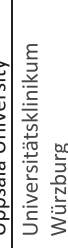 & & 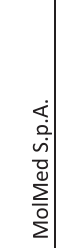 & 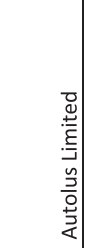 & 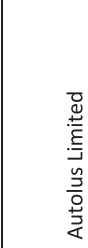 & 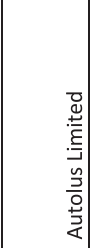 & 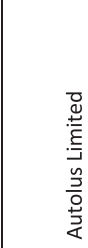 & 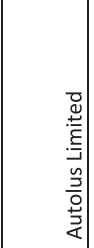 & 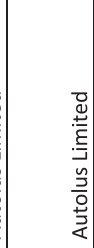 \\
\hline 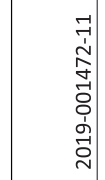 & & 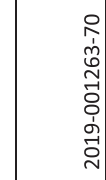 & 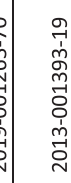 & $\begin{array}{l}0 \\
0 \\
0 \\
0 \\
0 \\
0 \\
0 \\
\vdots \\
0 \\
0 \\
0\end{array}$ & $\begin{array}{l}0 \\
0 \\
\hat{y} \\
0 \\
0 \\
0 \\
0 \\
0 \\
0\end{array}$ & 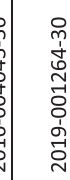 & & 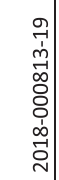 & $\begin{array}{l}\text { m. } \\
0 \\
0 \\
0 \\
\vdots \\
0 \\
\dot{0} \\
\vdots \\
0\end{array}$ & $\begin{array}{l}\overrightarrow{7} \\
\text { d. } \\
0 \\
\stackrel{0}{0} \\
0 \\
0 \\
\stackrel{\sim}{0}\end{array}$ & 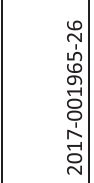 & 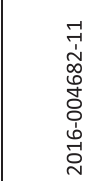 & $\begin{array}{l}\mathfrak{y} \\
\vdots \\
0 \\
0 \\
0 \\
0 \\
\vdots \\
\vdots \\
\vdots\end{array}$ & 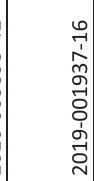 \\
\hline $\begin{array}{l}-1 \\
0 \\
o \\
0 \\
\bar{y} \\
0 \\
z \\
z\end{array}$ & 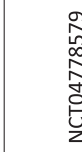 & & 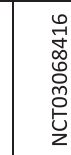 & 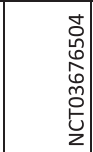 & & 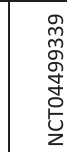 & & 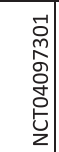 & $\begin{array}{l}\text { un } \\
\mathbf{s} \\
0 \\
\tilde{0} \\
\tilde{0} \\
\underline{z} \\
z\end{array}$ & $\begin{array}{l}\text { I } \\
\infty \\
0 \\
\tilde{N} \\
\tilde{0} \\
z\end{array}$ & 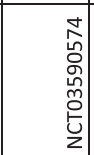 & & 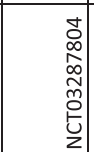 & 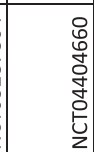 \\
\hline 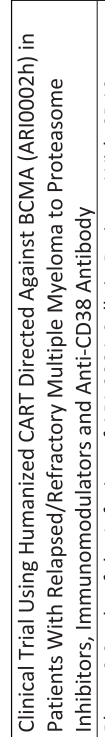 & 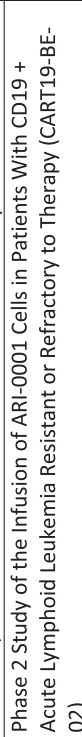 & 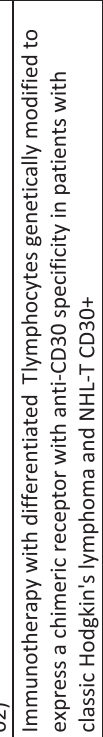 & 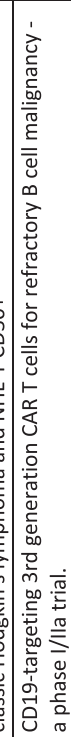 & 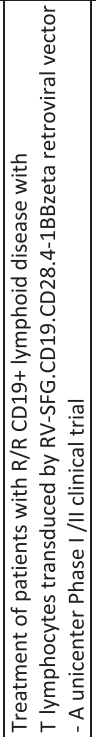 & 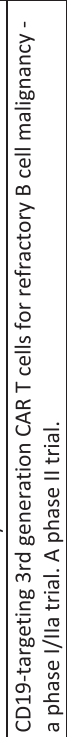 & 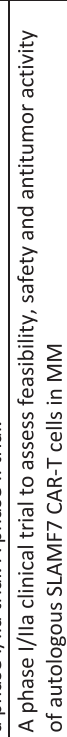 & 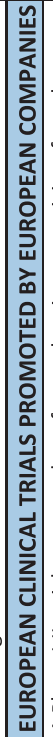 & 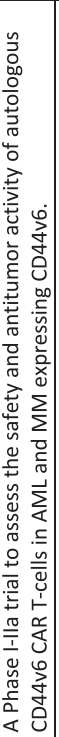 & 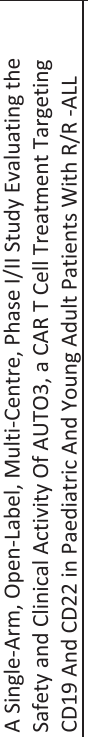 & 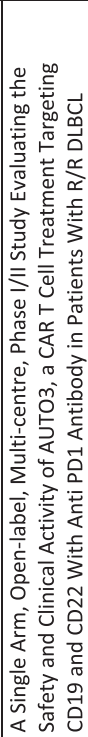 & 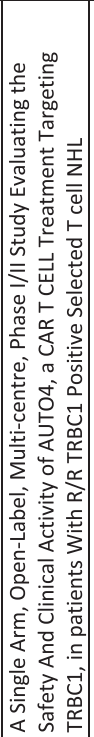 & 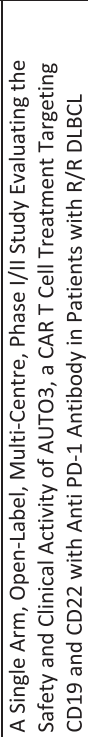 & 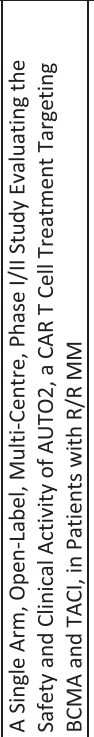 & 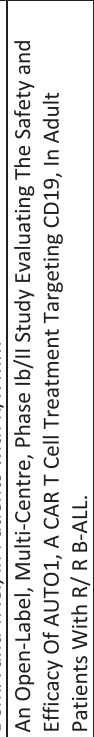 \\
\hline
\end{tabular}




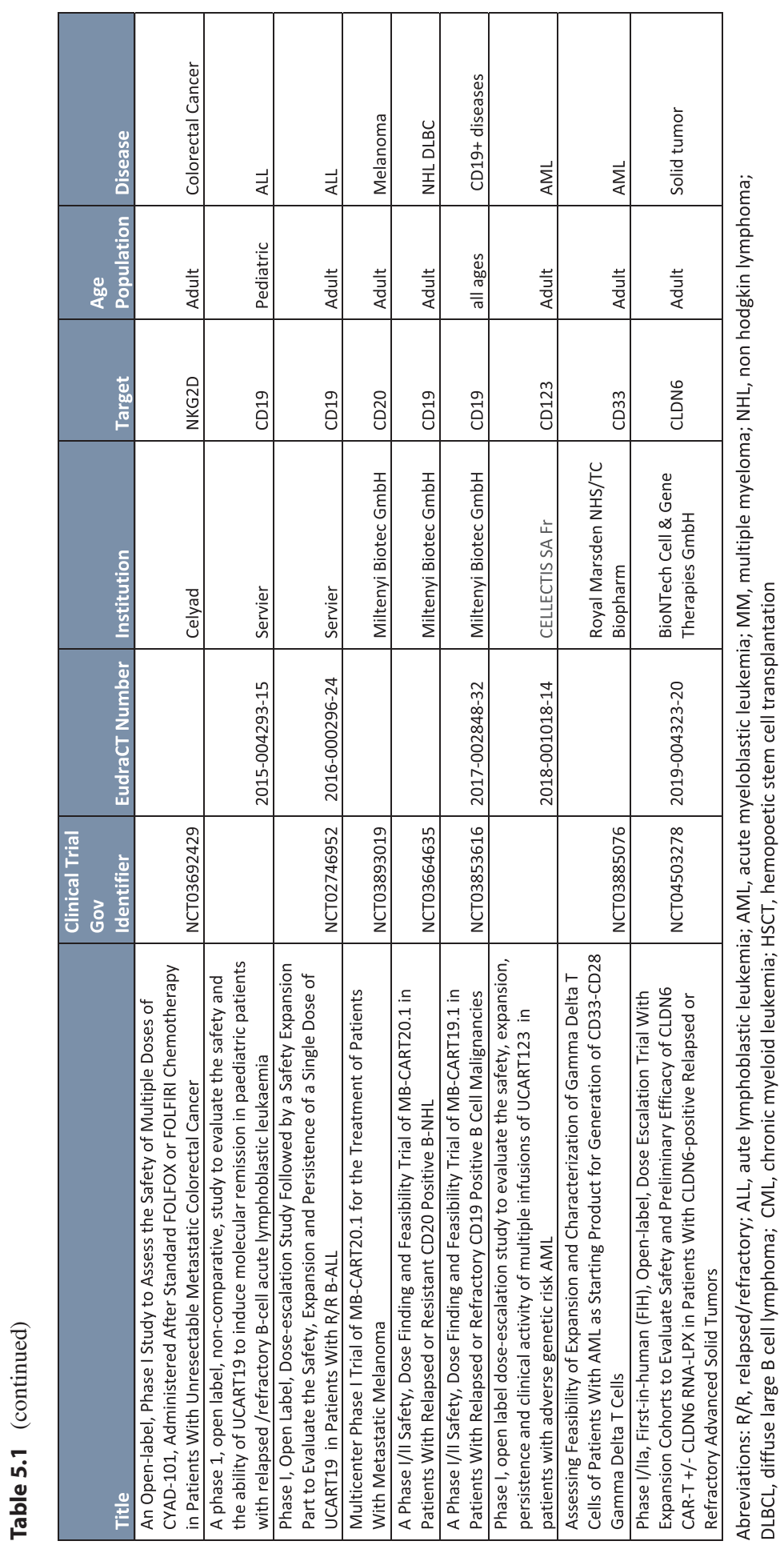


Twelve European institutions are responsible for the 20 academic clinical trials (University College London, $n=4$; Hospital Clinic of Barcelona, $n=3$; Great Ormond Street Hospital, $n=2$; Bambino Gesù, $n=2$; University of Uppsala, $n=2$; King's College, $n=1$; Matilde Tettamanti, $n=1$; Hospital Sant Pau, $n=1$; University of Heidelberg, $n=1$; and University of Wurzburg, $n=1)$. The most frequent target is CD19 ( $n=12$; for ALL, $n=5$; NHL, $n=1$; all B-lymphoid neoplasms, $n=6$ ). Other targets are BCMA ( $n=1$; MM), CD30 ( $n=1$; HL and T-NHL), SLAMF7 ( $n=1 ; \mathrm{MM}), \operatorname{GD} 2$ ( $n=2$, neuroblastoma), $\operatorname{ErbBR}(n=1$, neck and head tumours), Fap ( $n=1$, mesothelioma), and IL-1 RAP ( $n=1$, CML). Of the 20 clinical trials, 8 only included adults, 5 only included children, and 7 included all ages.

There were 16 additional clinical trials promoted by seven European pharma companies (Autolous, $n=6$; Miltenyi, $n=3$; Servier, $n=2$; MolMed, $n=1$; Celyad, $n=1$; Cellectis, $n=1$; TcBiopharm, $n=1$, BioNTech, $n=1$ ). Again, the most frequent target is $\operatorname{CD} 19$ ( $n=4$; for ALL, $n=2$; NHL, $n=1$; all B-lymphoid neoplasms, $n=1)$. Other targets are dual CD19/CD20 or CD19/CD22 $(n=3 ;$ ALL, $n=1$; NHL, $n=2), \operatorname{CD} 20$ ( $n=2$; melanoma, lymphoma), BCMA $(n=1 ; \operatorname{MM}), \operatorname{CD} 123(n=1$; $\mathrm{AML}), \mathrm{CD} 33$ ( $n=1, \mathrm{AML}), \mathrm{NKG} 2 \mathrm{D}(n=1$, colon cancer), CD44v6 ( $n=1, \mathrm{MM})$, TRCDB1 ( $n=1, \mathrm{~T}-\mathrm{NHL})$, and CLDN6 ( $n=1$; colon cancer).

Hopefully, this list will grow as more clinical trials are set up. We intend to compile an ad hoc workshop to provide more comprehensive data, such as the characteristics of the genetic construct (type of costimulatory molecule, 2nd- or third-generation CAR), the vector (viral or nonviral), and the method of expansion (automated or manual) and the plans of these groups to go beyond a particular clinical trial (hospital exemption, EMA). We believe this information will be useful to increase efforts and fuel this field in Europe.

Two initiatives have recently been launched to foster collaboration and increase CART activity in Europe: GoCART and T2 EVOLVE Consortium.

GoCART is a strategic partnership between EBMT and EHA that includes a multistakeholder coalition of patient representatives, health care professionals, pharmaceutical companies, regulators, health technology assessment (HTA) bodies, reimbursement agencies, and medical organizations. Some of its most important aims include the following:

- Collaborate and share data and knowledge.

- Promote harmonization of data collection, education, standards of care, regulatory approval, centre qualification, and reimbursement processes.

- Set up a pre- and postmarketing registry that supports regulatory and shared research purposes.

- Develop a cellular therapy education and information program for patients and health care professionals.

T2EVOLVE is an alliance of academic and industry leaders in cancer immunotherapy under the European Union's Innovative Medicines Initiative (Supported from the European Union's Horizon 2020 Research and Innovation Programme). The key objective of T2EVOLVE is to accelerate development and increase the 
awareness and access of cancer patients to immunotherapy with immune cells that harbour a genetically engineered TCR or CAR. Simultaneously, T2EVOLVE aims to provide guidance on sustainable integration of these treatments into the EU health care system. The T2EVOLVE consortium aims to achieve its goal by working on and improving the state of the art in the following key aspects:

- Selection of optimal lymphodepletion regimens.

- Optimization of preclinical models for the best safety and efficacy prediction.

- To involve and guide patients throughout their clinical journey.

- Definition of gold standard analytical methods pre- and post-engineered T cell infusion.

- Production of GMP guidance and establishment of standard product profiles.

- To produce excellent cancer therapies accessible to all European patients.

\section{Key Points}

1. Two initiatives have been launched to foster collaboration and increase CART activity in Europe: GoCART and T2 EVOLVE Consortium.

2. A large number of CAR-T cell clinical trials are underway.

3. Most clinical trials are occurring in the USA and China, and although Europe has lagged behind, there is evidence of increasing activity.

4. Initiatives to enhance clinical trial activity and cooperation across Europe are needed, and various initiatives are planned to facilitate this.

\section{References}

Grupp SA, Kalos M, Barrett D, et al. Chimeric antigen receptor-modified T cells for acute lymphoid leukemia. N Engl J Med. 2013;368:1509-18.

Locke FL, Ghobadi A, Jacobson CA, et al. Long-term safety and activity of axicabtagene ciloleucel in refractory large B-cell lymphoma (ZUMA-1): a single-arm, multicentre, phase 1-2 trial. Lancet Oncol. 2019;20:31-42. https://doi.org/10.1016/S1470-2045(18)30864-7.

Porter DL, Levine BL, Kalos M, et al. Chimeric antigen receptor-modified T cells in chronic lymphoid leukemia. N Engl J Med. 2011;365:725-33.

Open Access This chapter is licensed under the terms of the Creative Commons Attribution 4.0 International License (http://creativecommons.org/licenses/by/4.0/), which permits use, sharing, adaptation, distribution and reproduction in any medium or format, as long as you give appropriate credit to the original author(s) and the source, provide a link to the Creative Commons license and indicate if changes were made.

The images or other third party material in this chapter are included in the chapter's Creative Commons license, unless indicated otherwise in a credit line to the material. If material is not included in the chapter's Creative Commons license and your intended use is not permitted by statutory regulation or exceeds the permitted use, you will need to obtain permission directly from the copyright holder.

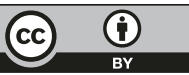

